Archived version from NCDOCKS Institutional Repository http://libres.uncg.edu/ir/asu/

\title{
Appalachỉan
}

B O O N E, N O R T H C A R O L I N A

\section{From Trash To Treasure And Beyond: The Meaning Of Voluntary Disposition}

\author{
By: Pia A. Albinsson and B. Yasanthi Perera
}

\begin{abstract}
Extant consumer research literature focuses on the subtleties, multiplicity of meanings, and values consumers attach to acquisition of personal possessions. Researchers have devoted less attention to consumers' disposition behaviors, including factors that influence disposition decisions. This paper explores voluntary disposition using data gathered through participant observations and in-depth interviews with a range of consumers, including those involved in clothing exchange (CE) events. The findings provide support for the a priori themes of values and consumption patterns, extending the life of self and goods, and consumers' self-concept. Additionally, the findings yield emergent themes of role transitions, role models and family patterns, and shared community. Utilizing our findings, and extant literature, we propose a conceptual Framework of Voluntary Disposition that can be utilized to analyze further meanings of consumer disposition patterns in different contexts.
\end{abstract}

Albinsson, P. A. and Perera, B. Y. (2009), From trash to treasure and beyond: the meaning of voluntary disposition. Journal of Consumer Behaviour, 8: 340-353. doi:10.1002/cb.301. Publisher version of record available at: https://onlinelibrary.wiley.com/doi/10.1002/cb.301 


\title{
From trash to treasure and beyond: the meaning of voluntary disposition
}

\author{
Pia A. Albinsson ${ }^{1 *}$ and B. Yasanthi Perera ${ }^{2}$ \\ ${ }^{1}$ Department of Marketing, Walker College of Business, Appalachian State University, Raley Hall \\ 4113, Boone, NC 28608, USA \\ ${ }^{2}$ Department of Management, College of Business, New Mexico State University, MSC 3DJ, Las \\ Cruces, NM 88003, USA
}

- Extant consumer research literature focuses on the subtleties, multiplicity of meanings, and values consumers attach to acquisition of personal possessions. Researchers have devoted less attention to consumers' disposition behaviors, including factors that influence disposition decisions. This paper explores voluntary disposition using data gathered through participant observations and in-depth interviews with a range of consumers, including those involved in clothing exchange (CE) events. The findings provide support for the a priori themes of values and consumption patterns, extending the life of self and goods, and consumers' selfconcept. Additionally, the findings yield emergent themes of role transitions, role models and family patterns, and shared community. Utilizing our findings, and extant literature, we propose a conceptual Framework of Voluntary Disposition that can be utilized to analyze further meanings of consumer disposition patterns in different contexts.

Key words: disposition, sharing, consumer self-concept, consumer identities, clothing exchanges

\section{Introduction}

I literally couldn't sleep the night before my first Clothing Exchange, I was so excited! I brought two huge bins of clothes, jewelry, and, shoes to donate. ... I had so much fun trying out other girls' things and took away a lot of neat things too. The fact that the hostess would donate any leftover items to a women's shelter made me bring a lot more

*Correspondence to: Pia A. Albinsson, Department of Marketing, Walker College of Business, Appalachian State University, Raley Hall 4113, Boone, NC 28608, USA.

E-mail: albinssonpa@appstate.edu than I initially would have. - Louise, 25-year old, female

The extant literature on consumer research explores a wide range of phenomena related to the consumption cycle. Featured prominently within this domain are consumers' product and experience-related acquisition behaviors (Thompson et al., 1989; Fischer and Arnold, 1990; Sherry, 1990; Otnes et al., 1997; Joy and Sherry, 2003), and negotiations of self-identity utilizing, for instance, messages imparted through branded images (McCracken, 1986; Belk, 1988; Kozinets, 2002; Grayson and Martinez, 2004). However, research on consumers' disposition behaviors, a natural com- 
ponent of the consumption cycle, such as "downshifting" (Schor, 1998), recycling, donating, and alternative use of goods, has received limited attention (Belk, 1988; Roster, 2001; Arnould and Thompson, 2005; Lastovicka and Fernandez, 2005). We contend that, despite recent efforts, further research is necessary to understand consumers' disposition behaviors. Thus, we examine voluntary disposition as it is lived and experienced by consumers to uncover different factors that guide disposition actions. Through integration of our findings with those in extant literatures, we posit a conceptual Framework of Voluntary Disposition and argue that consumers manage consumption by engaging in five modes of disposition: sharing, exchanging (trading), donating, recycling, and ridding (trashing).

\section{Disposition}

The disposition literature features topics ranging from gift giving (Sherry, 1983; Belk, 1995; Giesler, 2006), to community building through toy libraries (Ozanne and Ozanne, 2008). Researchers have also examined consumers' disposition of possessions to friends, family, and strangers (Price et al., 2000; Lastovicka and Fernandez, 2005); disposal of maternity wear (Gregson and Beale, 2004); disposition behaviors of the terminally ill (Pavia 1993; Kates, 2001), "packrats" and "purgers" (Coulter and Ligas, 2003), and the elderly (Price et al., 2000). These works highlight the importance of relationships in voluntary disposition. For example, "packrat" consumers are more apt to gift items with sentimental value to close friends or relatives to maintain ties with the object (Coulter and Ligas, 2003). In disposition behaviors of the terminally ill, bequeathing possessions to a close network of friends, akin to a family, provides a means of preserving memories of the loved one that had passed (Kates, 2001). Additionally, older consumers' disposition decisions are predicated upon an interplay of their perceptions of mortality, meanings associated with their special possessions, and relationships to others, especially family members (Price et al., 2000).

Earlier studies also address the "value" of goods in disposition (Price et al., 2000; Kates, 2001; Roster, 2001; Coulter and Ligas, 2003). Accordingly, an object's value stems from various attached meanings: utilitarian value based on usefulness; enjoyment value from the capacity to give pleasure; symbolic value derived from signifying interpersonal ties, and memories; and value derived from the object in expressing, or reinforcing, one's sense of self (Richins, 1994).

In reinforcing the latter, extant literature indicates that consumers' meaningful possessions are a part of their extended selves that may serve as anchors for individuals' selfconcept (Belk, 1988). Consumers may dispose of objects when the meaning they impart no longer "fits" the consumer's self-concept (Roster, 2001) or when the self no longer requires the assistance of an object to anchor its identity (Belk, 1988). Similarly, Schor (1998: p. 22), in writing about "downshifters" who voluntarily simplify their lifestyles, argues, "Downshifting brings one's lifestyle into correspondence with one's values." Lastovicka and Fernandez (2005: p. 816) note a range of consumer valuations of goods, presumably based on self-concept, including "never-me" and "undesired-past-me." Additionally, some individuals are only comfortable in selling unwanted items to buyers with whom they share a common identity (for instance, similar profession) (Lastovicka and Fernandez, 2005). Based on the connection between selfconcept and possessions in extant literature, we argue that self-concept is also prominent in consumers' disposition decisions. For example, a consumer who conceives of herself as an environmentalist may tend to engage in recycling and exchanging, as opposed to ridding.

In our study, we explore the importance of relationships, values, and self-concept in consumers' disposition behaviors. To do so, we focus our attention on the "Permanent Disposition" component of Jacoby et al. (1977) Disposition Decision Taxonomy, and 
address two subcategories, "Give it away" and "'Trade it." In their discussion, Jacoby et al. (1977: p. 28) pondered whether the product value to "society as a whole could be increased by educating consumers to dispose of products. ... in ways which satisfy the conservation ethic rather than simply by throwing or discarding said items." This study purports to address this by examining how consumers voluntarily dispose of their possessions.

Most studies to date examine disposition in relation to daily life and ordinary surroundings, while only a few explore disposition events. Specifically, Herrmann (1997) and Lastovicka and Fernadez (2005) study disposition through garage/yard sales, Sherry (1990) and Belk et al. (1988) explore disposition in the context of flea markets/ swap meets, all of which involve monetary transactions. Lastovicka and Fernadez (2005) call for research that examines voluntary disposition that does not involve financial transactions. Our research responds, in part, to this call by exploring disposition in an exchanging/trading community. As disposition may be forced due to external circumstances, for instance economic hardship or spousal pressure, we stress that the sole focus of our study is disposition that is voluntary in nature.

\section{Metbod}

\section{Clothing exchange events}

To investigate voluntary disposition, we gathered data from numerous informants, including participants of "Clothing Exchange" (CE) events. These events, which entail swapping items while socializing, occur in a range of locations from small American towns to international metropolises such as New York, Paris, and Milan (Atterberry, 2008; La Vie Verte, 2008). CEs are similar to communitydriven gift exchanges because both activities confirm relationships through social interactions (Hollenbeck et al., 2006). Prior to the events, participants examine their possessions and select items that they are willing to part with, including clothes, accessories, and household goods, using the rule "if it is good enough to donate, you can bring it." After each event, participants donate remaining items to various local charities. During the CEs, consumers voluntarily dispose of their possessions while acquiring others' possessions in the bargain. However, we specifically focus upon their disposition decisions and lived experiences through participating in CEs. Though we explain CEs in detail, our sample also includes informants who did not participate in these events. Therefore, the primary focus of our study is voluntary disposition, and not a specific mode, or context, of disposition.

\section{Location and sample}

We used purposive sampling when selecting informants (Glaser and Strauss, 1967; Lincoln and Guba, 1985). The locale of the study, a southwestern American university town, attracted diverse individuals. Our initial sample, consisting mainly of women, therefore included informants from Italy, India, Chile, England, Spain, Sweden, and Puerto Rico in addition to a diverse group of Americans. The international participants had resided in the United States between two and a half to twenty years. Participants were of different socioeconomic statuses, and of varying ethnicities and ages. See Table 1 for profiles of select participants (pseudonyms are used). The following section describes the research design and data collection conducted during three different phases spanning two years.

The study progressed in several stages following the process outlined by Schouten (1991). First, we examined the extant literature and conducted six phenomenological-like unstructured interviews to define our research direction and a priori themes. Second, we identified emergent themes through participant observation, additional in-depth interviews, and narratives to expand our understanding of consumer disposition patterns.

The a priori themes sensitized the researchers to the meaning consumers attach to 
Table 1. Participant profiles

\begin{tabular}{llll}
\hline Pseudonym & Gender/Age/Country & Education/Occupation & Data \\
\hline Leesa & F/30/USA & BS/Restaurant manager & Interview/Narrative \\
Cindy & F/39/England & PhD/GIS-specialist & Narrative \\
Rosa & F/34/Mexico & MBA/Ph.D. student & Narrative \\
Clint & M/22/USA & BBA/student & Narrative \\
Tereza & F/31/USA & MS/Lab technician & Narrative \\
Maria (host) & F/30/USA & MA/PR-coordinator & Interview/Narrative \\
Faye & F/44/USA & BA/Physical therapist & Interview/Narrative \\
Lucy & F/30/Italy & PhD/Researcher & Interview/Narrative \\
Jessica & F/28/Puerto Rico & MS/Environmental specialist & Interview/Narrative \\
Pauline & F/32/USA & PhD/Educator & Interview/Narrative \\
Jane & F/35/India & MS/Educator & Interview/Narrative \\
Sarah (host) & F/31/Sweden & MBA/Retail manager & Interview/Narrative \\
Richard & M/55/USA & MS/Software engineer & Narrative \\
Cole & M/39/USA & MS/Software specialist & Narrative \\
Martha & F/28/Chile & MS/Water/Soil engineer & Narrative \\
Melissa & F/38/Spain & PhD/English professor & Interview/Narrative \\
Louise & F/25/USA & BBA/Ph.D. student & Interview/Narrative \\
Gloria & F/33/USA & AA/Administrator & Narrative \\
& & & \\
\hline
\end{tabular}

possessions and the various issues disposition entails. In the initial interviews, informants frequently mentioned clothing items, and we subsequently heard of CEs that deepened our interest in investigating consumer voluntary disposition. The themes uncovered in the first phase were the "Need for purging and de-cluttering, "Doing something good" with unwanted items, "Extending the life of self and goods, and issues relating to consumers' "Selfconcept." We later collapsed the themes of "Need for purging and de-cluttering," and "Doing something good" to "Values and consumption patterns" to better reflect our findings.

Next, we became active participants in the CEs through meeting a cofounder of the local CE community. Maria, a former AmeriCorps volunteer, was amazed at the massive quantities of donated clothing funneled through her organization's offices. This experience prompted her to reflect upon the prevalent "throw away" attitudes in society, and her own consumption/disposal patterns that led to her starting CEs in her community. In contrast to public events held in cosmopolitan cities where consumers pay to participate, we studied CEs conducted in the homes of informants without monetary exchange.
During this phase, the first author participated in six events and the second author participated in three events. Prior to the CE event, participants merchandised goods attractively by category (i.e., jewelry, skirts, shoes) to create a "shopping" experience (see Appendix, Photo 1); during the CE, participants laughed, chatted, and encouraged each other to try on new things (Photo 2); and leftover items were set aside for donation (Photo 3).

During the second phase, we also interviewed twelve additional informants about their CE experiences and their overall disposition patterns. As in the initial interviews, we used phenomenological interview techniques to understand the true experiences of consumers as they are "lived" (Thompson et al., 1989). In phenomenological interviews, the participants are free to share about their experiences without the researcher guiding the process. The digitally recorded interviews were transcribed immediately after each meeting. Both authors kept individual notes of their experiences, and interviewed different informants.

In the final phase, we shared individual notes from earlier phases and conducted follow-up interviews with select participants to clarify their lived experiences. These 
interviews were semi-structured and based on themes that emerged in the previous phases. Additionally, we distributed semi-structured open-ended questionnaires via email to 45 male and female consumers in the participants' extended networks who were uninvolved in CEs to examine their experiences of voluntary disposition including alternative ways of disposition. Thirty-two individuals responded with narratives of their personal disposition stories. These narratives added richness to the data as "culture 'speaks itself' through an individual's story" (Riessman, 1993: p. 5). These narratives were particularly important in understanding voluntary disposition beyond the CE context.

The different phases of data collection spanned two years (February 2007-February 2009) and resulted in 327 pages of data. We conducted independent iterative readings of the materials, and compared and contrasted the findings before discussing discrepancies. In addition to utilizing several research methods, member checks (Lincoln and Guba,
1985) that allow informants to reflect and comment on their perceptions of the accuracy of the researchers' interpretations were also conducted.

\section{Findings}

Through our iterative analysis of the data, we posit a conceptual Framework of Voluntary Disposition (see Figure 1). Our re-named a priori themes are "Values and consumption patterns" (Need for purging/ de-cluttering and Doing something good), "Extending the life of self and goods," and consumers' "Self-concept," and our emergent themes are "Role transitions," "Role models and family patterns," and "Shared community." These themes are presented in the following section under the different components of the framework which influence consumer disposition decisions: Individual characteristics, Community characteristics, and Item characteristics.

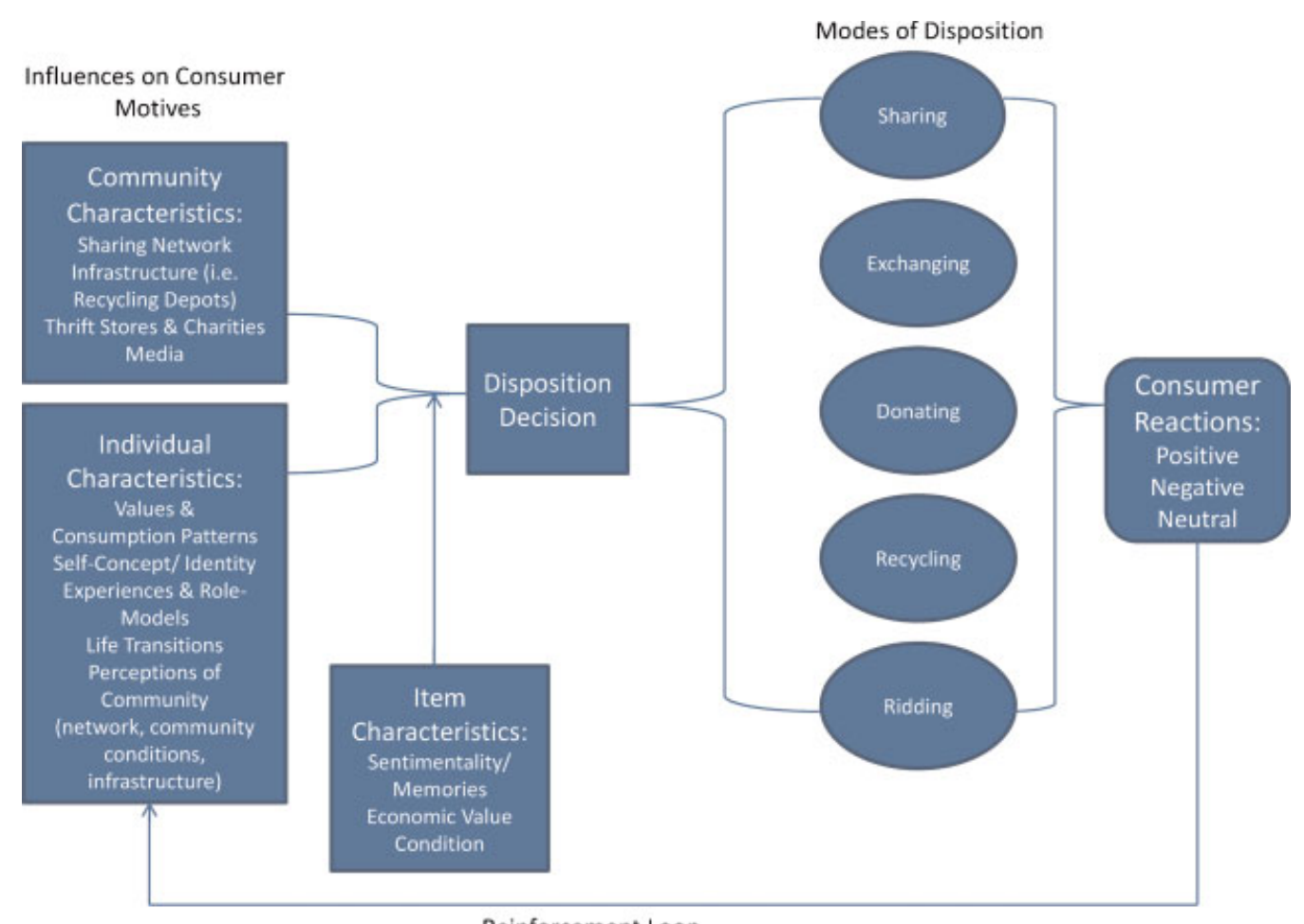

Reinforcement Loop

Figure 1. Framework of voluntary disposition. 


\section{Individual characteristics}

The individual characteristics component of the voluntary disposition framework includes values and consumption patterns, self-concept, experiences, role models, and individuals' perceptions of the context in which they live.

\section{Values and consumption patterns}

Individual and societal values were a recurring theme in our data. In terms of individual values, consumers' purging and de-cluttering activities were driven by various desires, including the need to simplify, keep up with trends, and make room for new belongings. One informant, Jane, reports:

When I am busy and stressed, the clutter builds up in my mind to the point I feel nauseous. ... clear spaces belp me to think,... everything has energy. ... so in clear spaces, I think the energy flow is so much better because there aren't any extraneous things to complicate matters and I am more thoughtful, calm, and creative.

Jane believes that even unseen things impart energy so she de-clutters frequently and does not hide clutter nor overcrowd her closets. Thus, for Jane, CEs provided an accessible mode of disposal. Additionally, her account introduces an alternative view of existence in terms of "energy" associations of objects unexplored in extant disposition literature.

Moreover, many informants indicated that individuals' values regarding what is truly important plays a significant role in disposition decisions. Leesa, who resisted discarding expensive clothes because of the money and effort expended in purchasing them, exemplified consumers' value related to money. Lucy, an Italian informant, shared "I have no problem ridding my closet of cheap stuff, but getting rid of real quality or designer items even if I never wear them or have grown out of them is a problem" because they were expensive. On a different vein, another informant, Sarah, had trouble discarding books, though she did not think twice about throwing out clothes, because of her respect for books.

Leesa and Sarah also spoke about the difference in individuals' values with the statement "someone's trash is another's treasure." This is an important point because this philosophy drives the CE phenomenon where consumers dispose of and acquire others' dispositions through exchange as new products. Cole, discussing his values of responsible consumption and sustainability, noted that he and his wife tried to find outlets that would allow others to benefit from their disposed items.

Several informants noted that CEs resonated with their values of altruism and social responsibility so they viewed these events as opportunities to "do something good." For example, Jessica believed that "by exchanging some of my clothes I am conserving some resources by not buying new" and Lucy, shared:

There are one or two dresses that I have given to friends that I one day boped to wear again, however, knowing that other people would actually use them makes me feel good. I think it is ecological in the true sense of $i t$. It is the best recycling experience I have ever had!

In terms of societal values, Cindy, a British respondent shared that in the United Kingdom:

People from the lower classes are less likely to wear cast-offs. ... you're more likely to see "upper" and "upper middle" classes wearing old clothes and buying second hand than "lower middle" and "working" classes. Also, there is a town/country split. ... Country folk are less bothered by image than city folk.

Cindy discussed generational differences in values between Gen Xers (like herself), her parents who remembered rationing, and the 
current generation who live in a "throwaway" society. In particular, she focused on the external influences shaping these generations such as WW II for her parents, and globalization, cheap imports, and easy credit for Gen Xers and Millenials. Cindy's reflections emphasize the influence of societal values and other external forces on individual disposition and acquisition behaviors. Additionally, Cindy raised the point of how individuals from different consumer segments can perceive second hand goods in widely different ways, for example as acceptable, or with disdain.

\section{Consumption patterns}

Several informants discussed the influence of their consumption patterns, often learned through family socialization, for example learning packrat behaviors from a parent with similar proclivities, on disposition behaviors. The integration of consumption patterns, individual values, and self-concept influenced disposition behaviors. For instance, Louise, driven by her fashionista self-concept and value of keeping up with trends shopped on a weekly basis. However, she also identified herself as a packrat but the stronger value of keeping up to date persisted and she disposed of her possessions on a regular basis through CEs and thrift stores to make room for new items. In contrast, Richard's father valued, and only "held on to good tools," thus setting an example for his son to keep only meaningful items. Richard, due to his discriminate consumption patterns, developed a liking for "traveling light," and, as a result, only held on to a few sentimental items such as the furniture hand-built by his father and father-inlaw. To maintain his preferred lifestyle, Richard frequently examines his possessions with a critical eye asking questions such as, "Have I worn this over the last year? Have I read this book enough times already?" to cull under-utilized items and dispose of them through thrift stores, rummage sales, and ridding.

\section{Self-concept}

Another informant, Sarah, expressed the importance of self-concept in acquisition and disposition behaviors. She shared:

I have all these clothes from different periods of my life. Sometimes I struggle with what I should keep and what I need to get rid of. I mean, I want to look professional and representative of my profession but I am not quite ready to give up the young, bip part of me.

Sarah exemplifies the connection between individuals' self-concept and their possessions. While she struggled with disposition decisions due to her conflicting identities (i.e., fashionable young person from her past vs. new professional), she acknowledged that her decisions to dispose of certain items from her past signaled a change, for better or worse, in who she used to be. Several other informants made disposition decisions based upon whether certain items "still fit" within their self-concept. Thus, individuals' self-concept, and their willingness to "let go" of their former selves, influence their disposition decisions.

\section{Extending life of self and goods}

Another supported a priori theme related to self-concept pertained to informants' disposition of cherished items with sentimental associations. For some, this sentimentality extended to clothes and they struggled to dispose of smaller sized clothing due to cherished memories of "when I was a size 6," and hopes of "reclaiming" their former size in the future. The CEs facilitated informants trying different "styles and identities." Jessica proudly showed off her jacket and hat while observing:

I used to think I bad a specific style in clotbing so when I came to the first exchange I boped to find similar things. But then, I was like, what the beck; I am going to try on totally different items and 
see bow I feel. Now, some of the items I picked up are my favorite items. I don't miss the old clothes that I donated at all; it actually gave me an opportunity to alter my identity a bit in a positive way.

Role transitions significantly influence selfidentity and social identity resulting in the individual's desire to change aspects of oneself (Young, 1991). Tereza expressed the ease with which she disposed of goods after a breakup, a job loss, and an impending move to a new job in another city. However, she found it difficult to dispose of possessions on a regular basis between these role transitions. Tereza's experiences are similar to those described by McAlexander (1991: p. 43) who studied the aftermath of divorce in terms of categories such as disposition to "break free" and "disposition to hold on."

\section{Role models and family patterns}

While Grønhøj (2006) reported the importance of family in consumers' green consumption practices, our conversation with Louise and several other informants revealed the importance of role models, family patterns, and formative experiences in acquisition and disposition behaviors. Louise, hailing from a "family of packrats," shared memories of "communal" dispositions where she, her sister, and mother would begin the process of ridding by boxing up items and hiding them in the garage before finally "letting go" of them. Many consumers dispose of items in stages to become accustomed to living without them (Roster, 2001; Lastovicka and Fernandez, 2005). In Louise's family, disposition was an emotional process endured for the sake of making space for new acquisitions and, as an adult, she yet engaged in similar disposition processes.

Clint, who echoed Louise's sentiments about familial role models, had trouble parting with his belongings and believed that his behaviors stemmed from years of watching his parents collecting "stuff' and keeping it long after it was obsolete. Now, Clint expressed dismay that these tendencies, developed through years of observing his parents, persisted. Collectively, Louise and Clint's examples illustrate the power of role models in acquisition and disposition behaviors.

\section{Perceptions of local community}

Consumers' perceptions of their local community were important in their disposition decisions. Martha perceived her community and the surrounding areas as being poor. As a result, she accumulated unwanted possessions for months at a time for donation, either locally or through relatives in Chile. Sarah perceived her community as lacking the infrastructure necessary for responsible disposition. Thus, though she was diligent about recycling glass, aluminum cans, and paper in her native Sweden where the infrastructure was available and recycling highly encouraged, she opted not to recycle in her current community because of her perceptions that the infrastructure was lacking, and took too much effort to seek out information.

\section{Community characteristics}

Our analysis stressed the importance of community characteristics in consumer disposition decisions. Factors such as the availability of an accessible sharing community, thrift stores, charities, and local infrastructure heavily influenced disposition decisions.

\section{Shared community (networks)}

Many informants cited the presence of a network community that encouraged exchanging as motivation for periodically disposing of possessions. Indeed, several informants noted that the social networking opportunities were an unexpected benefit of the CE parties. Maria shared:

It is really a sharing activity and almost a bonding activity. Always after an 
exchange, my friends and I will call each other or share on Facebook what we are wearing from the exchange.

In a related point, Jane believed that in addition to expanding social networks, CEs are about negotiating relationships because of the trust and respect necessary for a roomful of people to dispose of, and acquire, belongings without any issues.

\section{Infrastructure and media}

Besides consumer perceptions of their community resources, the actual availability of recycling infrastructure, for example, influence consumer disposition. In addition, local and global media addressing various issues such as the drawbacks of over-consumption, or consumer-driven community activities such as food/ clothing drives for the homeless, influence consumer disposition. Similar to Sarah, Martha shared that though she preferred to recycle her unwanted items due to values relating to sustainability, she often ridded items such as glass containers in the garbage because her town lacked a glass recycling facility. Other individuals used items that could not be recycled in their local community for alternative purposes instead of immediately resorting to ridding. For example, Rosa's family members collected colorful plastic packaging, such as chips bags, for an acquaintance that used them in making chic handbags.

\section{Thrift stores and charities}

The presence of thrift stores and charities accepting non-monetary donations also influence individuals' disposition decisions. Several informants indicated that the presence of such organizations, often integrated with altruism, compelled them to periodically sort through their belongings and donate items that were no longer useful. For example, Jane indicated that the ease with which items could be donated to organizations, for example Salvation Army with 24-hour drop-off boxes, motivated her to sort, and dispose of unwanted possessions. Other informants indicated that the presence of thrift stores, or even national chains that bought used goods from consumers, encouraged them to exchange or rid of unwanted items in order to accrue some benefit, (e.g., feeling good, monetary rewards, store credit).

\section{Item characteristics}

The characteristics of the possessions in question featured prominently in the disposition decisions of most informants. Specifically, the sentimental, economic, and symbolic value of an object and its condition influenced consumers' disposition decisions. While Leesa did not have sentimental attachment to her possessions and could easily discard them, other informants expressed difficulty in parting with items that held sentimental or important symbolic associations. For example, Melissa could not part with any of her friends' handmade gifts despite her small apartment. Similarly, Richard, a former gymnast and current fitness enthusiast, could not dispose of "shirts that have sentimental value. ... for instance, ones I wore on the gym team in high school" thereby demonstrating the importance of both sentimental and symbolic value of items in dispositions decisions. Other informants, such as Gloria, spoke of the economic value of goods as factoring into her dispositions decisions. She shared:

\section{Sometimes it is difficult to decide if I want to get rid of $i t$... I have a computer that crashed a couple of months ago. I haven't decided what to do with it; it's in good condition, but doesn't work. I don't want to just get rid of it because it cost me $\$ 700$... I replaced it with a laptop but I could still try to fix it and use it.}

Finally, for many, the actual condition of the item influenced disposition decisions. Rosa, for example, felt bad for discarding clothes in good condition so she, similar to Martha, kept them until she visited her native Mexico for 
distribution to needy individuals. However, Rosa was comfortable throwing away her son's toys and electronics because "they're usually in bad shape by the time we discard them."

\section{Discussion and conclusion}

The posited framework consists of three components that influence consumers' voluntary disposition practices: individual characteristics including self-concept, item characteristics, and community characteristics including societal and market-mediated messages and availability of local infrastructure. Our findings indicate that, based on individual characteristics, particular consumers may prefer a specific mode of disposition such as donating to charity, sharing items among friends and family, recycling through internet free-cycle websites, exchanging, or simply ridding. However, our analysis indicates that although individual characteristics influence both disposition decisions and mode of disposition, the community and item characteristics drive most disposition decisions.

In terms of CEs, consumers, ranging from fashionistas to minimalists, attend these events primarily to exchange and dispose of used goods. In alignment with prior research, our findings indicate that informants' motives for participation ranged from altruistic to agonistic (Sherry, 1983). Some consumers attended CEs due to purely hedonistic motives such as socializing, eating, drinking, and acquiring new products without much effort. Two informants, Louise and Sarah, a self-disclosed "chronic shopaholic" and a "professional shopper," brought many items to the CEs, explored the disposed items with curiosity, were creative in combining different styles, and helped other participants in trying on new styles. Several consumers identified themselves as a mix between purgers and packrats in that they did not experience much difficulty in disposing of their possessions when the opportunity to acquire new goods arose.

In contrast, others considered the CEs as opportunities for practicing sustainable living on a local and 'doable' level. The informants who valued altruism and doing good made quicker disposition decisions and experienced less difficulty in "letting go" of their possessions, compared to those who did not claim altruistic values. Financial and time constraints, as well as the misperception that sustainability practices would require a significant amount of effort and additional resources, deterred some from engaging in sustainability practices. However, through engaging in CEs, these consumers felt more connected to global sustainability issues and perceived that they, albeit at a local level, were contributing to these efforts. This finding partly addresses Jacoby et al.'s (1977) question in that providing consumers with opportunities to dispose of items in responsible ways accrue benefits to society.

As Gregson et al. (2007) argue, voluntary disposition practices are normative and are influenced by the consumer's life stage. As participants are often acquainted, CEs entail controlled disposal or transfer where givers have some measure of control with regard to the recipients of their possessions (Price et al., 2000). We contend that the primary motivation underlying this tendency for controlled disposal or transfer stem from the consumers' view of their possessions as extended selves (Belk, 1988). Disposition occurs more readily when the parties involved share a common identity (Lastovicka and Fernandez, 2005). We posit that CE participants constitute an "ingroup" with a shared self-concept because many are friends or colleagues. Therefore, in this context, possessions transform from being "mine" to "ours." In absence of CEs, some consumers indicated that they either would donate their possessions to a charity or thrift store, or, if they did not want to exert the additional effort, would discard the items as trash regardless of their condition. Therefore, in terms of encouraging responsible disposition, we see value in the existence of these sharing networks in communities.

Interestingly, informants Pauline and Clint, who did not participate in the CE groups, could dispose of their possessions more easily 
when they approached the process in stages. While they acknowledged that their disposed possessions would be of use to a stranger, they first wanted to share these items with those in their social circle before donating to charitable organizations. Thus, these informants essentially created their own informal sharing network. This desire was also observed in CEs when certain participants would retrieve their unclaimed possessions saying, "Oh, I will bring it back next time; I prefer that someone I know gets it." These finding correspond with those of Price et al. (2000) where consumers use control tactics in transferring possessions to others. Moreover, when considering that some aspect of the owner remains in the gift after an exchange (Gregory, 1982; Mauss, 1990), controlled transfer presents a means through which consumers extend the life of their favorite items (Belk, 1995) by influencing specific individuals to acquire them by the end of the CE event.

Our informants discussed five modes of voluntary disposal: ridding items beyond repair, recycling, donating to charities, sharing their belonging with others, and exchanging items within a network. Moreover, consumers' reactions to disposition (positive, negative, or neutral) via a given mode influenced their future disposition decisions and disposition mode. For instance, Jane was reluctant to participate in CEs due to beliefs that the "owner's energy imbued his or her possessions" and was unsure about claiming others' possessions. However, she enjoyed her first CE after she became acquainted with the participants and liked them so it was acceptable to claim their possessions. Jane's positive experience caused her to re-evaluate her consumption values and self-concept as someone who does not acquire second hand possessions, and prompted her to engage in this disposition mode again.

\section{Directions for future research}

In terms of future research, first, we need an indepth understanding of those aspects of consumer disposition behaviors that are stable and transfer from one context to another, and those that are transitory and depend on factors of convenience. For example, Iyer and Kashyap (2007) suggest that both external (i.e., incentives and information) and internal factors in combination with consumers' individual characteristics influence recycling behavior. To this end, Sarah recycled in her former community where recycling infrastructure was easily accessible and believed this to be an integral aspect of her identity. However, she resorted to ridding because her current community lacked the necessary resources. Thus, a better understanding of stable and transitory factors that influence disposition would allow social marketers to effectively target consumers in regards to responsible disposition.

Second, we need to explore individual characteristics and external influences that were unexamined in this study such as how culture influences disposition behaviors especially in terms of disposition mode. Additionally, several consumers likened CEs to online sharing websites (e.g., freecycle.com and Craigslist.com). The on-line context, and the influence of technology on disposition, presents another avenue of study. Finally, while Putnam (2000) discusses society's declining social capital, we contend that CEs enhance social capital through the expansion of social networks and 'recycled consumption' that represent the rising tide of conscientious consumerism. Thus, exploring the social capital aspect of CEs and sharing networks present an opportunity for future study.

\section{Biographical notes}

Pia A. Albinsson (Ph.D. New Mexico State University) is Assistant Professor of Marketing at Appalachian State University. She researches advertising effectiveness, community networks, socially responsible consumer behavior, and green consumption practices.

B. Yasanthi Perera is a Ph.D. Candidate in the Department of Management at New Mexico State University. Her research interests 
include social entrepreneurship, sustainability, consumer and corporate social responsibility.

\section{References}

Arnould EJ, Thompson CJ. 2005. Consumer culture theory (CCT): twenty years of research. The Journal of Consumer Research 31 (4): 868-882.

Atterberry W. 2008. Eat, drink, and swap your clothes! Available at http://www.cnn.com/2008/ LIVING/homestyle/11/14/tf.clothing.swap/ [accessed on 17 November 2008].

Belk RW. 1988. Possessions and the extended self. Journal of Consumer Research 15 (September): 139-168.

Belk RW. 1995. Collecting in a Consumer Society. Routledge: London.

Belk RW, Sherry JF, Wallendorf M. 1988. A naturalistic inquiry into buyer and seller behavior at swap meet. Journal of Consumer Research 14 (March): 449-470.

Coulter RA, Ligas M. 2003. To retain or to relinquish: exploring the disposition practices of packrats and purgers. Advances in Consumer Research 30: 38-43.

Fischer E, Arnold SJ. 1990. More than a labor of love: gender roles and Christmas gift shopping. Journal of Consumer Research 17: 333-345.

Giesler M. 2006. Consumer gift systems. Journal of Consumer Research 33 (September): 283-290.

Glaser BG, Strauss AL. 1967. The Discovery of Grounded Theory. Aldine: Chicago.

Grayson K, Martinez R. 2004. Consumer perceptions of iconicity and indexicality and their influences on assessment of authentic market offerings. Journal of Consumer Research 31 (September): 296-313.

Gregory CA. 1982. Gifts and Commodities. Academic Press: London.

Gregson N, Beale V. 2004. Wardrobe matter: the sorting, displacement, and circulation of women's clothing. Geoforum 35 (6): 689-700.

Gregson N, Metcalfe A, Crewe L. 2007. Moving things along: the conduits and practices of divestment in consumption. Transactions of the Institute of British Geographers 32 (2): 187-200.

Grønhøj A. 2006. Communication about consumption: a family process perspective on 'green' consumer practices. Journal of Consumer Behaviour 5: 491-503.
Herrmann G. 1997. Gift or commodity: what changes hands in the U.S. garage sale. American Ethnologist 24 (4): 910-930.

Hollenbeck CR, Peters C, Zinkhan GM. 2006. Gift giving: a community paradigm. Psychology $\&$ Marketing 23 (7): 573-595.

Iyer ES, Kashyap RK. 2007. Consumer recycling: role of incentives, information, and social class. Journal of Consumer Behaviour 6: 32-47.

Jacoby J, Berning CK, Dietvorst TF. 1977. What about disposition? Journal of Marketing April: 22-28.

Joy AS, Sherry JF. 2003. Speaking of art as embodied imagination: a multi-sensory approach in understanding aesthetic experience. Journal of Consumer Research 28 (9): 239-256.

Kates SM. 2001. Disposition of possessions among families of people living with AIDS. Psychology $\varepsilon$ Marketing 18 (4): 365-387.

Kozinets RV. 2002. Can consumers escape the market? Emancipatory illuminations from Burning Man. Journal of Consumer Research 29 (June): 28-30.

Lastovicka J, Fernandez FV. 2005. Three paths to disposition: the movement of meaningful possessions to strangers. Journal of Consumer Research 31 (March): 813-823.

Lincoln YS, Guba EG. 1985. Naturalistic Inquiry. Sage: Beverly Hills, CA.

Mauss M. 1990. The Gift: The Form and Reason for Exchange in Archaic Societies, trans. Halls WD (ed.). Routledge: London.

McAlexander JH. 1991. Divorce, the disposition of the relationship, and everything else. Advances of Consumer Research 18: 43-48.

McCracken G. 1986. Culture and consumption: a theoretical account of the structure and movement of the cultural meaning of consumer goods. Journal of Consumer Research 13 (June): 7184.

Otnes C, Lowrey T, Shrum LJ. 1997. Towards an understanding of consumer ambivalence. Journal of Consumer Research 24 (September): 8093.

Ozanne LK, Ozanne JL. 2008. Building community within a toy library: the pleasures of sharing. Presentation at the $3^{\text {rd }}$ Annual Consumer Culture Theory Conference, Boston, MA.

Pavia T. 1993. Dispossession and perceptions of self in late stage HIV infection. Advances in Consumer Research 20: 425-428. 
Price LL, Arnould EJ, Curasi CF. 2000. Older consumer's disposition of special possessions. Journal of Consumer Research 27 (September): 179-201.

Putnam R. 2000. Bowling Alone: The Collapse and Revival of American Community. Simon and Schuster: NY.

Richins ML. 1994. Valuing things: the public and private meanings of possessions. Journal of Consumer Research 21 (December): 504-521.

Riessman CK. 1993. Narrative Analysis. Sage: Beverly Hills, CA.

Roster CA. 2001. Letting go: the process and meaning of dispossession in the lives of consumers. Advances in Consumer Research 28 (1): 425430.

Schor J. 1998. The Overspent American: Why We Want What We Don't Need. Basic Books: New York.

Schouten JW. 1991. Selves in transition: symbolic consumption in personal rites of passage and identity reconstruction. Journal of Consumer Research 17 (March): 412-425.

Sherry JF. 1983. Gift giving in anthropological perspective. Journal of Consumer Research 10 (September): 157-168.

Sherry JF. 1990. A sociocultural analysis of a Midwestern flea market. Journal of Consumer Research 17: 13-30.

Thompson CJ, Locander WB, Pollio HR. 1989. Putting consumer experience back into consumer research: the philosophy and method of existential-phenomenology. Journal of Consumer Research 16 (2): 133-146.

Young D. 2008. La Vie Verte. Tips for sustainable living from cash-strapped Parisians. Available at http://lavieverte.wordpress.com/2008/06/23/tipsfor-sustainable-living-from-cash-strapped-parisians/ [accessed on 10 November 2008].

Young MM. 1991. Disposition of possessions during role transitions. Advances in Consumer Research 18: 33-39.

\section{Appendix}

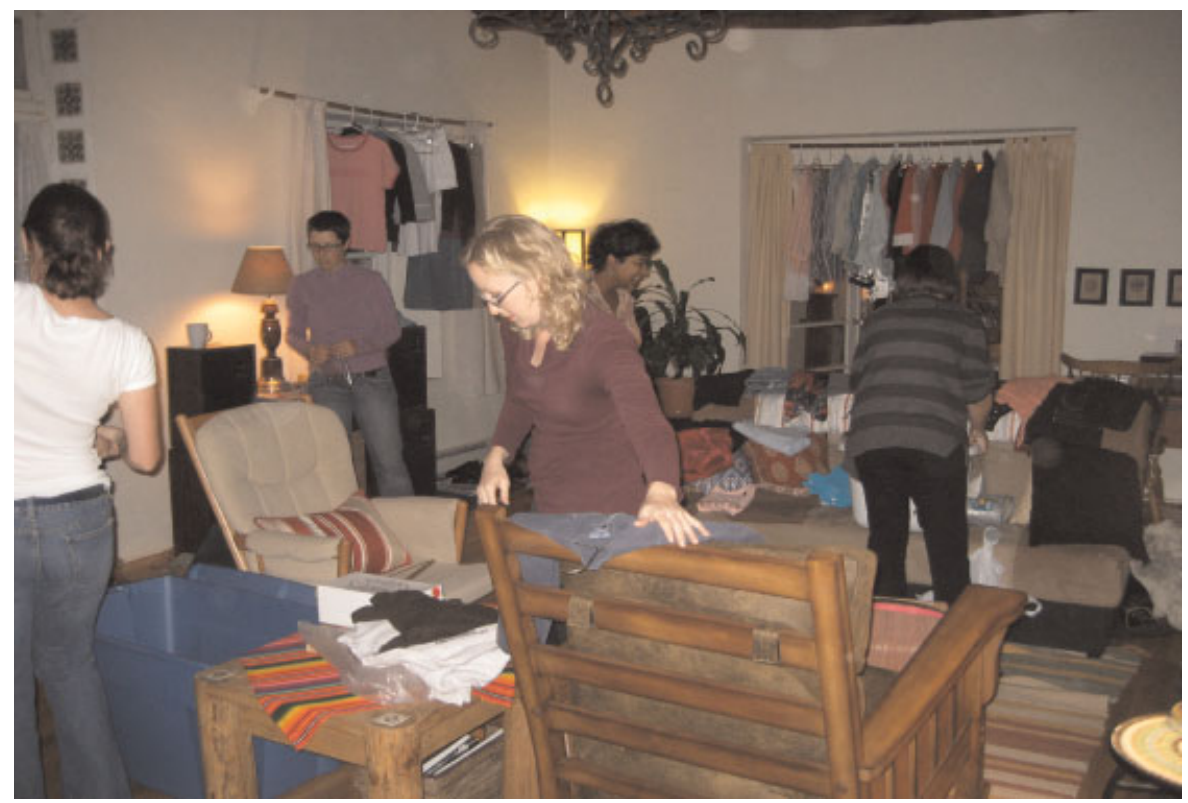

Photo 1. Merchandising CE 2, 2007. 


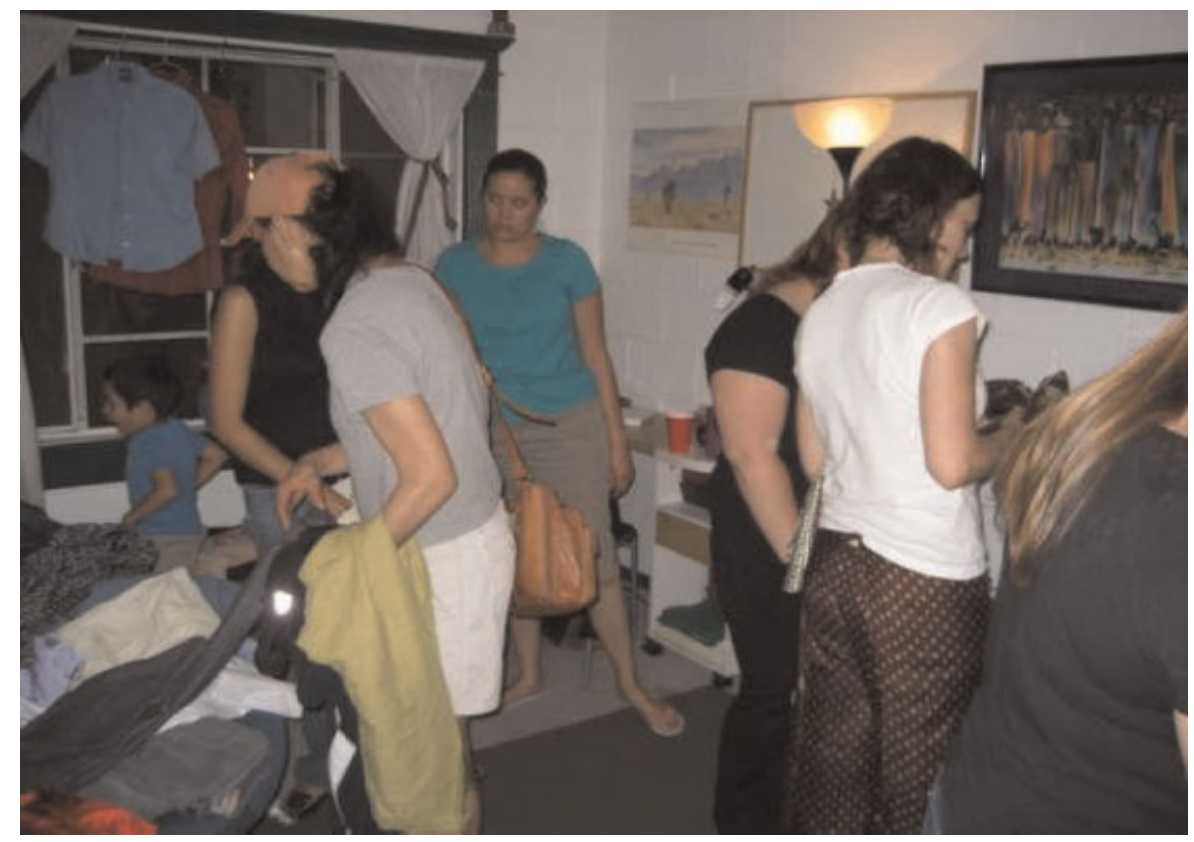

Photo 2. Exchange CE 6, 2009.

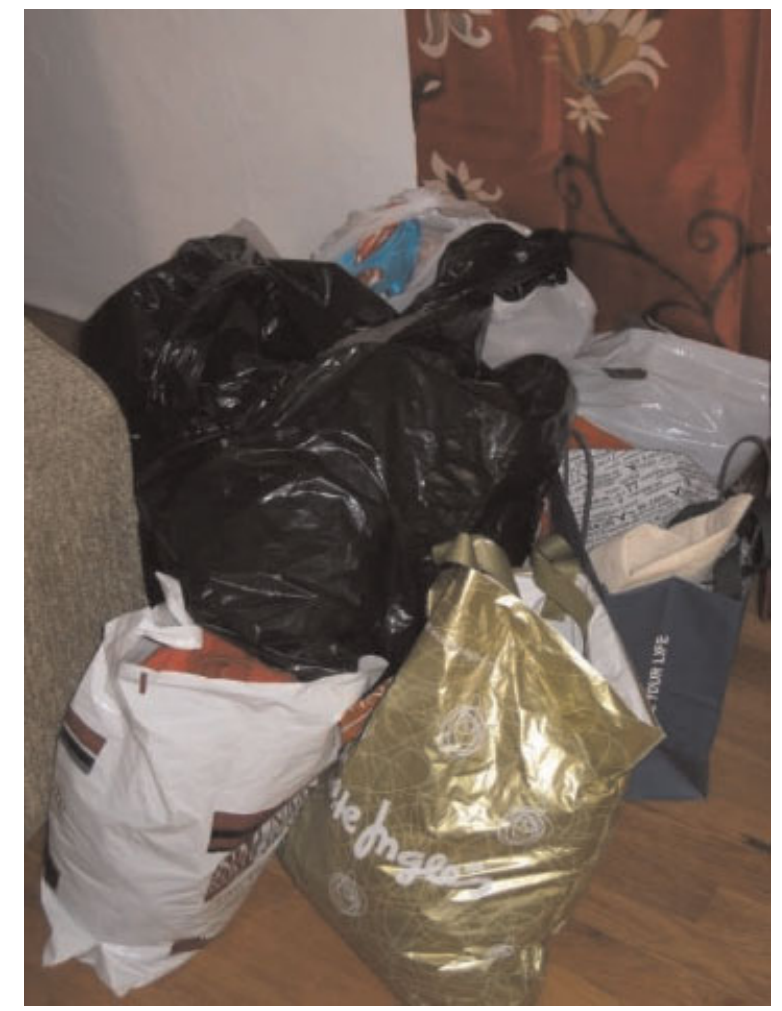

Photo 3. Donations CE 42008. 